Article

\title{
Tidal Current Energy Resources off the South and West Coasts of Korea: Preliminary Observation-Derived Estimates
}

\section{Do-Seong Byun ${ }^{1, *}$, Deirdre E. Hart ${ }^{2}$ and Woo-Jin Jeong ${ }^{3}$}

1 Ocean Research Division, Korea Hydrographic and Oceanographic Administration, Haeyang-Ro, Yeongdo-Gu, Busan 606-806, Korea

2 Department of Geography, University of Canterbury, Private Bag 4800, Christchurch 8140, New Zealand; E-Mail: deirdre.hart@canterbury.ac.nz

3 Nautical Chart \& Hydrographic Division, Korea Hydrographic and Oceanographic Administration, Haeyang-Ro, Yeongdo-Gu, Busan 606-806, Korea; E-Mail: oujin@korea.kr

* Author to whom correspondence should be addressed; E-Mail: dsbyun@korea.kr; Tel.: +82-51-400-4350; Fax: +82-51-400-4195.

Received: 20 November 2012; in revised form: 4 January 2013 / Accepted: 17 January 2013 / Published: 24 January 2013

\begin{abstract}
In this study we estimate the prospective tidal current energy resources off the south and west coasts of Korea and explore the influence of modeling tidal current energies based on 15-day versus month-long data records for regimes with pronounced perigean/apogean influences. The tidal current energy resources off southern and western Korea were calculated using 29-day in situ observation data from 264 stations. The resultant annual energy densities found at each station were categorized into six groups, with a greater percentage of sites falling into the lower-energy groups: $1.1 \%$ for $>10 \mathrm{MWh} \cdot \mathrm{m}^{-2}$; $2.7 \%$ for 5 to $10 \mathrm{MWh} \cdot \mathrm{m}^{-2} ; 6.8 \%$ for 3 to $5 \mathrm{MWh} \cdot \mathrm{m}^{-2} ; 9.1 \%$ for 2 to $3 \mathrm{MWh} \cdot \mathrm{m}^{-2}$ and $80.3 \%$ for $<2 \mathrm{MWh} \cdot \mathrm{m}^{-2}$. Analysis shows that the greatest concentration of high annual energy densities occurs in the Jeonnam Province coastal region on the western tip of southwest Korea: $23 \mathrm{MWh} \cdot \mathrm{m}^{-2}$ at Uldolmok, $15 \mathrm{MWh} \cdot \mathrm{m}^{-2}$ at Maenggol Sudo, $9.2 \mathrm{MWh} \cdot \mathrm{m}^{-2}$ at Geocha Sudo and $8.8 \mathrm{MWh} \cdot \mathrm{m}^{-2}$ at Jaingjuk Sudo. The second highest annual energy density concentration, with $16 \mathrm{MWh} \cdot \mathrm{m}^{-2}$, was found in Gyudong Suro, in Gyeonggi Province's Gyeonggi Bay. We then used data from the 264 stations to examine the effect of perigean and apogean influences on tidal current energy density evaluations. Compared to derivations using month-long records, mean annual energy densities derived using 15-day perigean spring-neap current records alone overestimate the annual mean energy by around $10 \%$ whereas those derived using only the apogean records underestimate energy
\end{abstract}


by around $12 \%$. In particular, accuracy of the $\mathrm{S}_{2}$ contribution to the energy density calculations is significantly affected by use of the 15-day data sets, compared to the $\mathrm{M}_{2}$ component, which is relatively consistent. Further, annual energy density estimates derived from 29-day records but excluding the $\mathrm{N}_{2}$ constituent underestimate the potential resource by about $5.4 \%$. Results indicate that one month of data is required to accurately estimate tidal current energy in regimes showing pronounced perigean and apogean differences in spring-neap tidal current patterns and that inclusion of the $\mathrm{N}_{2}$ constituent in calculations is preferable. This finding has widespread applicability for green energy resource assessments, for example, in regions of the Unites States Atlantic coast and in New Zealand.

Keywords: tidal currents; tidal current energy; perigean and apogean; spring-neap tides

\section{Introduction}

Tapping into renewable energy resources has become a key global priority as fossil fuels become scarcer and human-induced climate changes accelerate. Oceans contain massive, perennially-renewed amounts of energy. The energy sources within the ocean-tides, tidal currents, waves and thermal or haline differences-potentially represent green, renewable energy resources for society. Tidal current energy is one of the best of these potential resources since: (a) its capture does not rely on the large scale constructions required for tidal energy capture, making it more environmentally friendly; (b) it is highly predictable relative to wind energy [1], with higher rates of energy extraction possible using smaller converters due to the 800 to 1000 times greater density of sea-water compared to air; and (c) importantly, tidal current energy is less vulnerable to seasonal and global climate changes than most other renewable energy sources [2,3]. Alongside these positives, there exists the potential for seabed effects, including sediment accumulation and associated ecological changes, in the lee of tidal current generators once energy harvesting begins. The significance of these effects needs to be investigated as a part of the detailed site-specific assessment of potential installations subsequent to an initial national energy resource assessment. Given the three identified positive attributes of tidal current energy, in countries bordered by tide-dominated coasts a logical first step in planning a sustainable energy future is to initiate a national tidal current energy resource assessment. Such assessments can help overcome the real-world challenges of locating, installing, operating and maintaining the necessary electricity capture facilities in optimal current speed environments.

Current speed is a key factor in site selection for tidal current energy developments. The European Commission developed an electronic database of global tidal current energy resources based on two selection criteria: that is, sites with a minimum economic operational velocity greater than $1 \mathrm{~m} \cdot \mathrm{s}^{-1}$ most of time [3] and those with maximum velocities greater than $1.5 \mathrm{~m} \cdot \mathrm{s}^{-1}$ [4]. These basic site selection criteria are subject to change due to oil price increases or technological developments. For example, recently, energy converters have been developed with high power-conversion ratios even under low current speeds $\left(0.25 \mathrm{~m} \cdot \mathrm{s}^{-1}\right)$, such as the Vortex Induced Vibrations for Aquatic Clean Energy (VIVACE) [5]. Additionally, Lunar Energy has developed a device called the Rotech Tidal Turbine with a venturi-shaped duct that acts as a tidal current accelerator [6]. With such technological 
changes in mind, understanding and refining our methods for assessing tidal current energy resources are essential first steps towards securing an energy future that is predictable and renewable.

This paper comprises a preliminary assessment of the tidal current energy resources of southern and western Korea, two regions characterized by tide-dominated regimes, based on 29-day in situ observation records from 264 stations (Figure 1). Further, we discuss the minimum observation record length needed to estimate tidal current energy resources in areas with distinct perigean and apogean spring-neap tidal current regimes.

Figure 1. Locations of the 264 current velocity observation stations used in this study.

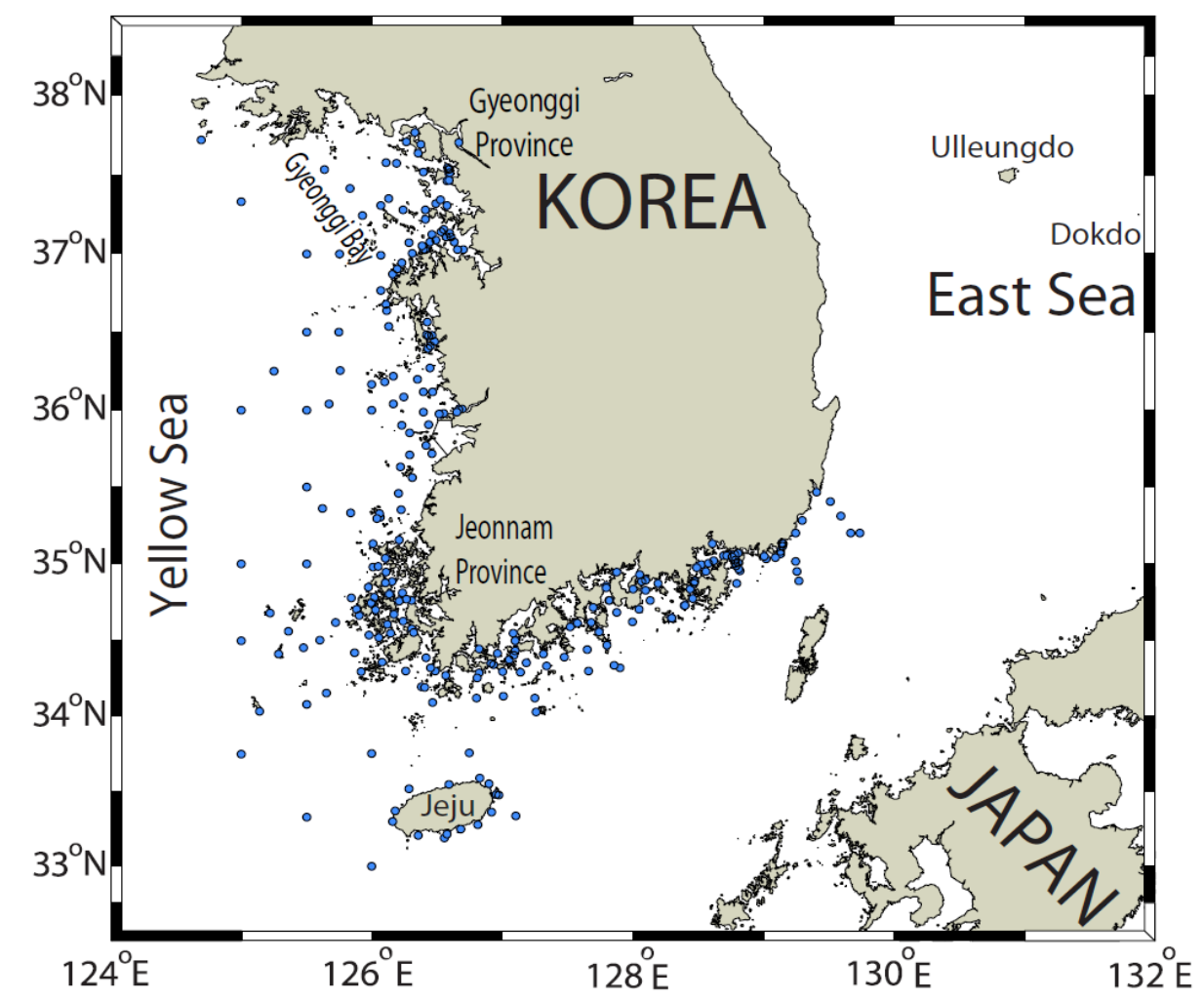

\section{Methodology}

The kinetic energy flux $\left(P_{\mathrm{ke}}, \mathrm{W}\right)$, which is an indication of the power available from the kinetic energy of water flowing through a cross-sectional area $A\left(\mathrm{~m}^{2}\right)$, can be expressed as $[4,7]$ :

$$
P_{\mathrm{ke}}=0.5 \rho A V_{\mathrm{sp}}^{3}
$$

where $\tilde{n}$ is sea-water density $\left(\mathrm{kg} \cdot \mathrm{m}^{-3}\right)$ and $V_{\text {sp }}$ is the speed of current-velocity $\left(\mathrm{m} \cdot \mathrm{s}^{-1}\right)$. The power density $\left(P_{\mathrm{d}}, \mathrm{W} \cdot \mathrm{m}^{-2}\right)$ of a tidal stream, representing the kinetic energy flux per unit square meter, is expressed as:

$$
P_{\mathrm{d}}=0.5 \rho V_{\mathrm{sp}}^{3}
$$

Using Equation (2), the energy density $\left(E_{\mathrm{d}}, \mathrm{Wh} \cdot \mathrm{m}^{-2}\right)$, over a certain period of time $(T)$ is given by:

$$
E_{d}=\int_{0}^{T} P_{d} \mathrm{~d} t
$$


Note that this approach is applicable to both rectilinear and rotating currents. In this study the tidal current energy resources of Korea's southwest coastal regime were estimated using current data collected approximately $5 \mathrm{~m}$ below the sea surface at intervals of 6,10,15 and $30 \mathrm{~min}$, for durations greater than a month, at 264 stations over the period from 1999 to 2011 . In general, the data quality was good: any spikes were removed via the phase-space thresholding method explained by Goring and Nikora [8], leading to $<5 \%$ gaps. Gaps were filled pre-processing using values predicted from T_TIDE [9], a program which harmonically analyzes and predicts tidal currents.

Monthly energy densities $\left(E_{\mathrm{Md}}, \mathrm{Wh} \cdot \mathrm{m}^{-2}\right)$ from the $k$-day observation data sets were calculated using Equation (3) as follows:

$$
E_{\mathrm{Md}}=\frac{1}{n} \sum_{D=1}^{k} \sum_{h=1}^{24} \sum_{m=1}^{n}\left[P_{d}\right]_{m, h, D}
$$

where $m, h$ and $D$ indicate minutes, hours and days, respectively, $k=29$ and $n=\frac{60 \mathrm{~min}}{\Delta t \min }$ with the $\Delta t$ data observed at $6,10,15$ and 30 min intervals. Most of the data (>90\%) were recorded at $10 \mathrm{~min}$ intervals. Subsequently, annual energy densities $\left(E_{\mathrm{Ad}}, \mathrm{Wh} \cdot \mathrm{m}^{-2}\right)$ were estimated by:

$$
E_{\text {Ad }}=365\left(\frac{E_{\mathrm{Md}}}{k}\right)
$$

\section{Results and Discussion}

\subsection{Spatial Distribution of Estimated Tidal Current Annual Energy Densities}

Since 1960, the Korea Hydrographic and Oceanographic Administration (KHOA, or pre-2009 the National Oceanographic Research Institute, NORI) has made annual measurements of ocean currents in the waters surrounding Korea in order to provide tidal current information, mainly for the purpose of navigation safety. In this study we collected a 264 monitoring station subset of the tidal current records from the west and south coasts of Korea (Figure 1) spanning 1999 to 2011, with each record being $>29$-day length and of good quality. The annual average energy density $\left(E_{\mathrm{Ad}}\right)$ was estimated for each site using Equation (5) and the individual station's pre-processing observational data. We subsequently produced an overview of the horizontal distribution of $E_{\mathrm{Ad}}$ around Korea by categorizing the annual average energy density results into six groups: high energy areas with $>10 \mathrm{MWh} \cdot \mathrm{m}^{-2}$; moderately-high energy areas with 5 to $10 \mathrm{MWh} \cdot \mathrm{m}^{-2}$; intermediate energy areas with 3 to $5 \mathrm{MWh} \cdot \mathrm{m}^{-2}$ and 2 to $3 \mathrm{MWh} \cdot \mathrm{m}^{-2}$; and low energy areas with $<2 \mathrm{MWh} \cdot \mathrm{m}^{-2}$. The resultant frequencies of occurrence of these categories across the 264 stations were: $1.1 \%$ for $>10 \mathrm{MWh} \cdot \mathrm{m}^{-2} ; 2.7 \%$ for 5 to $10 \mathrm{MWh} \cdot \mathrm{m}^{-2}$; $6.8 \%$ for 3 to $5 \mathrm{MWh} \cdot \mathrm{m}^{-2}$; $9.1 \%$ for 2 to $3 \mathrm{MWh} \cdot \mathrm{m}^{-2}$; and $80.3 \%$ for $<2 \mathrm{MWh} \cdot \mathrm{m}^{-2}$.

These results reveal that environments exhibiting very high annual tidal current energy densities are likely to be relatively rare around Korea. Figures 2 and 3 show the greatest concentration of high-energy density sites was found off the coast of Jeonnam Province: including the highest energy density of $53 \mathrm{MWh} \cdot \mathrm{m}^{-2}$ in Uldolmok (Myungryang Strait); $9.0 \mathrm{MWh} \cdot \mathrm{m}^{-2}$ in the Geocha Waterway; and $6.9 \mathrm{MWh} \cdot \mathrm{m}^{-2}$ in the Jaingjuk Waterway. Additionally, the high energy density of $7.9 \mathrm{MWh} \cdot \mathrm{m}^{-2}$ was found in the Maenggol Waterway, which was only estimated from 15-day observation data. 
Figure 2. Spatial distribution of the 29-day tidal current observation-derived annual energy densities.

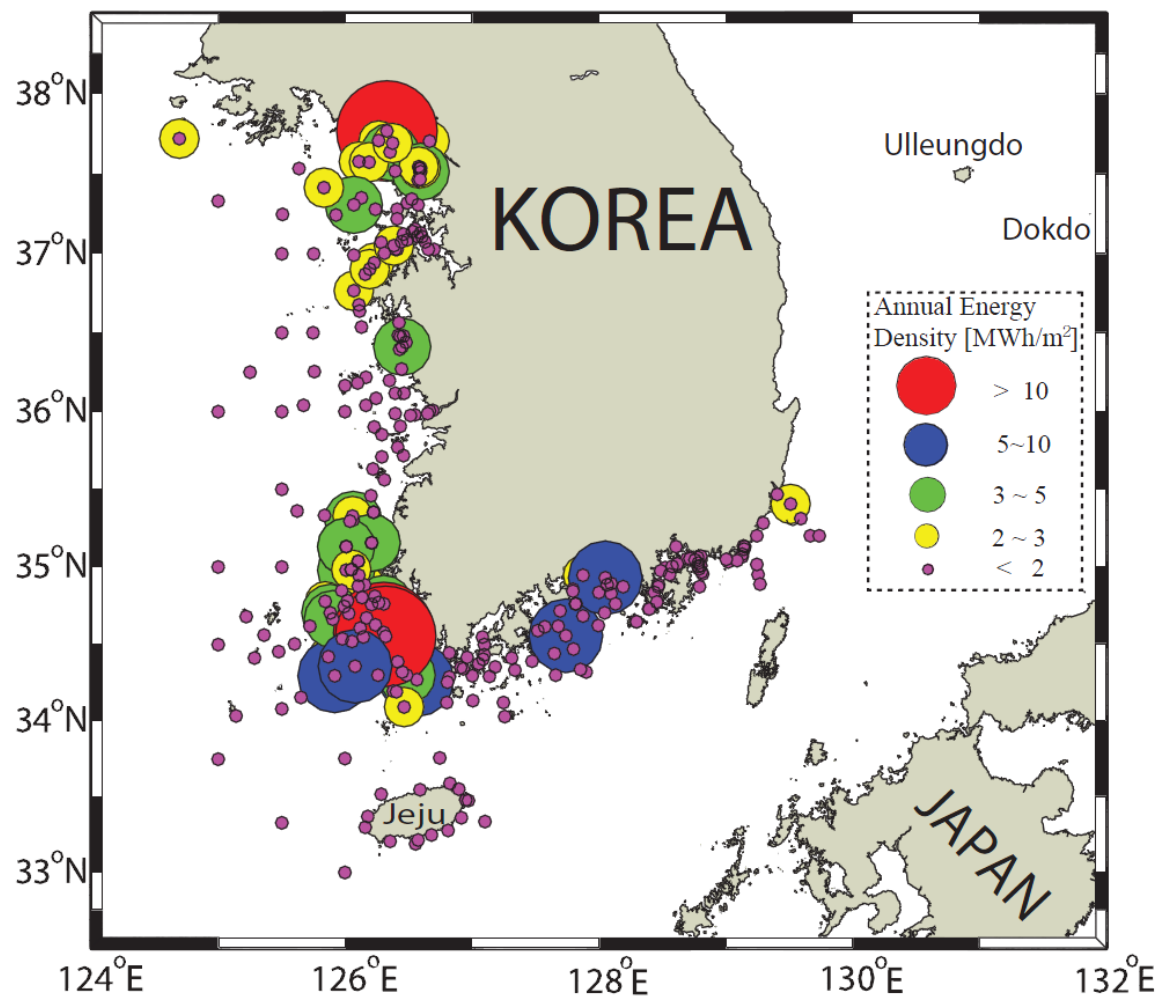

This area has a mean spring tidal range of around $3 \mathrm{~m}$. The Gyudong Waterway, which is located in Gyeonggi Bay and has a mean spring tidal range of $>8 \mathrm{~m}$, exhibited the second highest annual average energy density: $16 \mathrm{MWh} \cdot \mathrm{m}^{-2}$. Results show that high annual average energy densities are mainly found in waterways characterized by narrow widths, since this bathymetry leads to strong, rectilinear tidal current flows. In addition, we noticed that the magnitude of the high velocity results was not closely related to tidal height ranges.

These results should be interpreted as general predictions of the spatial distribution of prospective energy resources around Korea, and not as precise local estimates, since they were estimated from surface velocities measured at single points. Additional information is needed to estimate the energy resource potentials of particular waterways, including their cross-section areas and mean tidal current velocities or power densities. We therefore suggest that the energy density information provided in Figures 2 and 3 is useful as a "first-cut" assessment tool to narrow the search for potential development sites, each of which require a complementary, in-depth local study.

In order to help narrow this search, we made rough estimates of the cross-sectional mean tidal current energy resources of the seven major waterways of Korea from simple calculations used in Triton Consultants Ltd. [2] as represented in Table 1. Results indicate that although Uldolmok exhibits the highest mean maximum velocity, it has less prospective energy resources (182 GWh) compared to Jaingjuk Waterway $(1014 \mathrm{GWh})$, which can attribute its 5.6 times greater potential to having the largest cross-sectional area of the waterways examined. This result suggests that a key step in selecting the best tidal energy development sites, in addition to tidal current analyses, is to examine the three dimensional bathymetry, including the potential cross-sectional area, horizontal area and water depth, where the generators can be installed. This finding is in line with Defne et al. [10] who explain that 
"... a larger area or a larger width across the currents is expected to accommodate more turbines than a smaller area. A larger depth allows for a larger size device that might lead to a larger power conversion".

Figure 3. Annual energy densities estimated from each tidal current-velocity observation station in the coastal regions of (a) Gyeonggi and (b) Jeonnam Provinces.
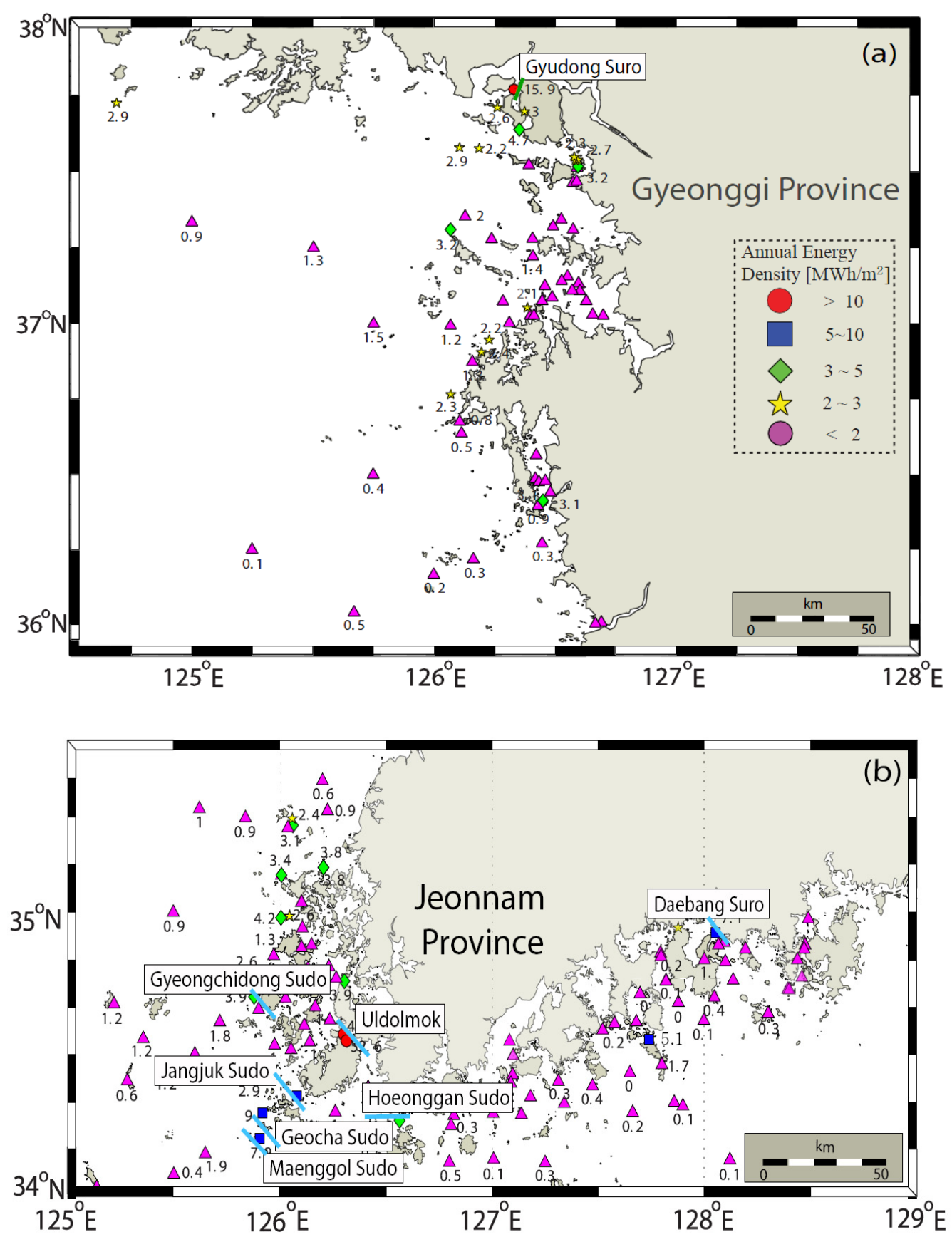
Table 1. Maximum flood $\left(V^{F}{ }_{\max }\right)$ and ebb $\left(V^{E}{ }_{\max }\right)$ currents estimated from 2011 tidal current predictions, channel cross-sectional areas $(A)$, and mean prospective cross-sectional power $\left(\overline{P_{d_{A}}}=\overline{P_{d}} \cdot A\right)$ and its annual energy $\left(\overline{E_{A_{A}}}\right)$ information, for Korean waterways identified as having relatively strong tidal currents.

\begin{tabular}{|c|c|c|c|c|c|c|c|}
\hline Waterway name & $\begin{array}{c}V_{\max }^{F} \\
\left(\mathbf{m} \cdot \mathbf{s}^{-1}\right)\end{array}$ & $\begin{array}{c}V_{\max }^{E} \\
\left(\mathbf{m} \cdot \mathbf{s}^{-1}\right)\end{array}$ & $\begin{array}{c}\overline{V_{\max }} \\
\left(\mathbf{m} \cdot \mathbf{s}^{-1}\right)\end{array}$ & $\begin{array}{c}\overline{P_{d}} \\
\left(\mathbf{k W} \cdot \mathbf{m}^{-2}\right)\end{array}$ & $\begin{array}{c}A \\
\left(\mathbf{m}^{2}\right)\end{array}$ & $\begin{array}{c}\overline{P_{d_{A}}} \\
\text { (MW) }\end{array}$ & $\begin{array}{c}\overline{E_{A_{A}}} \\
(\mathbf{G W h})\end{array}$ \\
\hline Gyudong & 2.91 & 2.29 & 2.08 & 0.84 & 23,100 & 19.31 & 169 \\
\hline Uldolmok & 4.12 & 3.40 & 3.01 & 2.53 & 8,225 & 20.79 & 182 \\
\hline Gyeongchidong & 2.00 & 1.85 & 1.54 & 0.34 & 81,750 & 27.73 & 243 \\
\hline Jangjuk & 2.25 & 1.98 & 1.69 & 0.45 & 257,300 & 115.76 & 1,014 \\
\hline Geocha & 2.12 & 2.05 & 1.67 & 0.43 & 40,000 & 17.24 & 151 \\
\hline Maenggol & 2.03 & 2.06 & 1.64 & 0.41 & 195,650 & 79.57 & 697 \\
\hline Daebang & 2.06 & 2.16 & 1.69 & 0.45 & 14,160 & 6.33 & 55 \\
\hline
\end{tabular}

Notes: Assuming that mean maximum cross-sectional and depth averaged current speed $\overline{V_{\max }}=0.8 \frac{\left(V_{\max }^{F}+V_{\max }^{E}\right)}{2}$ and mean power density $\overline{P_{d}}=\frac{1}{2} \frac{4}{3 \pi} \frac{\left(0.9 \overline{V_{\max }}\right)^{3}+\left(0.5 \overline{V_{\max }}\right)^{3}}{2} \rho$ with $\rho=1025 \mathrm{~kg} \cdot \mathrm{m}^{-3}[2]$.

\subsection{Characteristics of the Tidal Currents and Power Energies at Representative Sites}

Tidal currents are the horizontal movement of water that accompanies the vertical changes in water level observed at the shore that we call the tides. Both vertical and horizontal water movements are mainly caused by astronomical phenomenon and, thus, they generally exhibit spring-neap tidal cycle effects due to the modulation of the $\mathrm{M}_{2}$ and $\mathrm{S}_{2}$ constituents. In this section we explore patterns of variability in tidal currents and their estimated power densities at Uldolmok and Gyudong stations, showing the first and second magnitudes of annual energy densities (Figures 2 and 3 ).

As shown in Figure 4, the Uldolmok and Gyudong Waterway are characterized by the strongest tidal current regimes in Korea due to their narrow widths: maximum current-speeds $>4.0 \mathrm{~m} \cdot \mathrm{s}^{-1}$ for Uldolmok and $>2.5 \mathrm{~m} \cdot \mathrm{s}^{-1}$ for Gyudong Waterway. In contrast to Gyudong Waterway, where current speeds drop during neap periods, in Uldolmok there is no significant neap reduction in maximum current speeds, with maximum tidal current speeds still reaching $>2 \mathrm{~m} \cdot \mathrm{s}^{-1}$. The strong neap currents in Uldolmok are mainly attributable to the occurrence of an unusually weak $S_{2}$ tidal current amplitude $\left(0.62 \mathrm{~m} \cdot \mathrm{s}^{-1}\right)$ relative to the $\mathrm{M}_{2}$ one $\left(2.73 \mathrm{~m} \cdot \mathrm{s}^{-1}\right)$, which is more than 4.4 times greater, as represented in Table 2 .

In addition, since the power density is in proportion to the cube of the current-speed as shown in Equation (2), the maximum power density during the spring tides is about three times greater than that of the neap tides in Uldolmok and Gyudong Waterways, respectively. Spring tides are, thus, the favored period in terms of the potential for generating energy resources. In addition, the power density estimates based on the predicted tidal currents at both stations show a similar magnitude of variability, with the exception of the $>1 \mathrm{~kW} \cdot \mathrm{m}^{-2}$ underestimation of power densities during the neap tides of both regimes. The stronger observed currents result from the highly dominant nature of these tidal regimes along with their narrow bathymetries. When examining the magnitude and variability of tidal current speeds alone, Uldolmok appears to be one of the most suitable sites for tidal current energy generation. 
Figure 4. One-month time series of (a,b) observed current speeds; (c,d) observation-derived power densities and (e,f) prediction-derived power densities in Uldolmok and Gyudong Waterways.
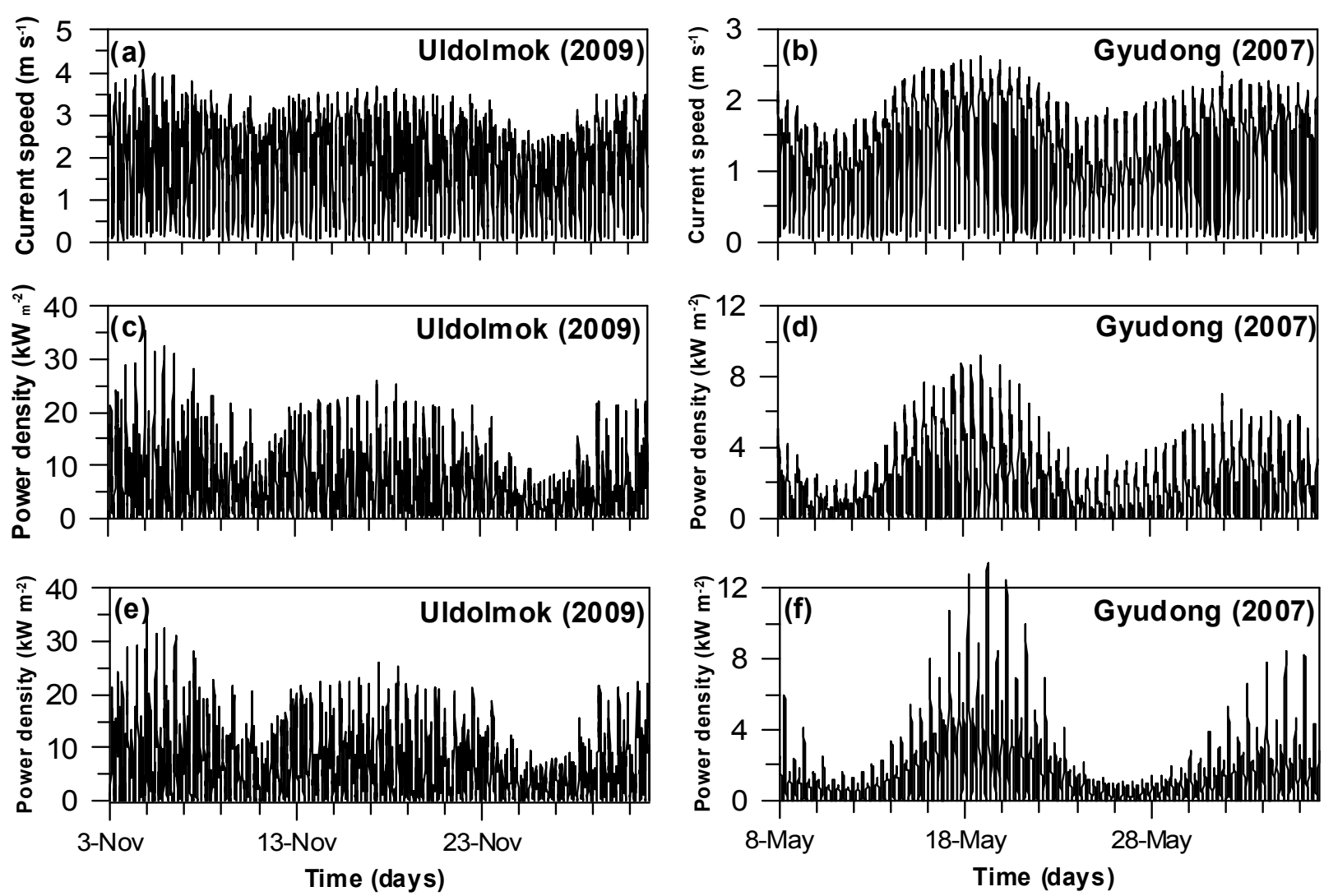

Table 2. The $\mathrm{M}_{2}$ and $\mathrm{S}_{2}$ harmonic analysis results of tidal current-velocities at Uldolmok and Gyudong Waterways, Korea.

\begin{tabular}{cccccc}
\hline \multirow{2}{*}{ Station } & \multirow{2}{*}{ Constituents } & \multicolumn{4}{c}{ Tidal current ellipse } \\
\cline { 2 - 6 } & & $a_{\max }\left(\mathrm{m} \cdot \mathrm{s}^{-1}\right)$ & $b_{\max }\left(\mathrm{m} \cdot \mathrm{s}^{-1}\right)$ & $\theta\left(^{\circ}\right)$ & $\varphi\left(^{\circ}\right)$ \\
\hline \multirow{2}{*}{ Uldolmok } & $\mathrm{M}_{2}$ & 2.73 & -0.03 & 133 & 254 \\
& $\mathrm{~S}_{2}$ & 0.62 & -0.01 & 131 & 321 \\
\multirow{2}{*}{ Gyudong } & $\mathrm{M}_{2}$ & 1.85 & -0.02 & 66 & 71 \\
& $\mathrm{~S}_{2}$ & 0.58 & 0.03 & 68 & 165 \\
\hline
\end{tabular}

Notes: $a_{\max }, b_{\max }, \theta$ and $\varphi$ indicate the semi-major axis, semi-minor axis, inclination and phase for the $\mathrm{M}_{2}$ and $\mathrm{S}_{2}$ tidal current constituents, respectively. Phases are referenced to $135^{\circ} \mathrm{E}$.

\subsection{Effects of Moon's Perigee and Apogee}

As shown in Figure 4, the speeds of two subsequent spring-neap tidal currents tend to be different. This is due to changes in the distance between the Moon and Earth induced by the moon's elliptical orbit around Earth, which has a period of 27.55 days. Tide-generating forces vary in inverse proportion to the third power of the distance between the Earth and the Moon. From the moon's perigee (the Earth-proximal orbit) to its apogee (the Earth-distant orbit) there is an approximately $13 \%$ change in the distance between the Moon and Earth. The resultant amplitudes of the perigean and apogean spring-neap tides in any single lunar month are, thus, different [11]. 
Table 3. Comparison of mean annual energy densities $\left(\overline{E_{A d_{-} M o b s}}\right)$ derived from 15-day apogean (Exp_asn) and perigean (Exp_psn) tidal current-velocity observation records versus those derived from 29-day records (Exp_msn), for 264 stations, and the corresponding predictions for total energy generated over twelve months $\left(\overline{E_{\text {Ad_Apre }}}\right)$.

\begin{tabular}{|c|c|c|c|c|}
\hline Experiments & 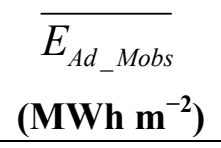 & $\begin{array}{c}\Delta \overline{E_{A d_{-} M o b s}} a \\
\mathbf{( \% )}\end{array}$ & 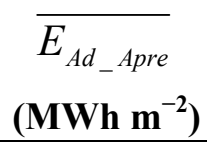 & $\begin{array}{c}\Delta \overline{E_{\text {Ad_Apre }}}{ }^{b} \\
\mathbf{( \% )}\end{array}$ \\
\hline Exp_asn & 1.216 & -12.5 & 0.971 & -15.1 \\
\hline Exp_psn & 1.532 & +10.2 & 1.221 & +6.8 \\
\hline Exp_msn & 1.390 & - & 1.144 & - \\
\hline
\end{tabular}

Notes: ${ }^{a} \Delta \overline{E_{A d_{-} M o b s}}$ and ${ }^{b} \Delta \overline{E_{A d_{-} A p r e}}$ are the variation rates of $\overline{E_{A d_{-} M o b s}}$ and $\overline{E_{A d_{-} A p r e}}$ in each experiment compared to those of Exp_msn.

The combination of the $\mathrm{M}_{2}$ and $\mathrm{S}_{2}$ tidal current constituents generates spring-neap tidal currents with a period of 14.76 days. The addition of the $\mathrm{N}_{2}$ constituent produces the perigean-apogean differences between subsequent spring-neap tidal currents occurring each month. Despite the importance of this monthly scale variation, estimates of tidal current energy density have tended to be made based on current data observed over single spring-neap cycles (i.e., $\sim 14$ days periods) [4].

In this section, we evaluate the impact of using observation data from only half a lunar month on the accuracy of energy density estimates. We do this via comparisons of the mean annual energy densities derived from perigean versus apogean spring-neap tidal current records, along with estimates derived from full-lunar-month long records.

Firstly, month-long current observations from 264 stations were split into two sets of 15-day records, one covering apogean spring-neap tidal current records and the other covering the perigean half of the records. Secondly, observation-derived annual energy densities were estimated using Equation (5) and the three different current records data sets: the apogean data set (Exp_asn); the perigean data set (Exp_psn); and the full 29-day data set (Exp_msn). In addition, 29-day prediction-derived annual energy densities were estimated using Equation (5) for the three different data sets.

The mean annual energy densities $\left(\overline{E_{A d_{-} M o b s}}\right)$ estimated from the three experiments were $1.216 \mathrm{MWh} \cdot \mathrm{m}^{-2}$ for Exp_asn, $1.532 \mathrm{MWh} \cdot \mathrm{m}^{-2}$ for Exp_psn, and $1.390 \mathrm{MWh} \cdot \mathrm{m}^{-2}$ for Exp_msn (Table 3). As expected, the experiment using the apogean (smaller amplitude) spring-neap data set leads to $\sim 12.5 \%$ underestimation of the energy resources compared to Exp_msn, while the experiment using the perigean (larger amplitude) spring-neap data set leads to $\sim 10.2 \%$ over-estimation.

The prediction-based annual energy estimates using the 15-day versus 29-day harmonic analyses revealed similar energy evaluation errors (Table 3$)$. These mean annual energy densities $\left(\overline{E_{\text {Ad_Apre }}}\right)$ show that, compared to using month-long records, using apogean data alone leads to a $15.1 \%$ underestimation of resources (i.e., $1.144 \mathrm{MWh} \cdot \mathrm{m}^{-2}$ for Exp_msn versus $0.971 \mathrm{MWh} \cdot \mathrm{m}^{-2}$ for Exp_asn), whereas using perigean data alone leads to a $6.8 \%$ overestimation (i.e., $1.221 \mathrm{MWh} \cdot \mathrm{m}^{-2}$ for Exp_psn). The differences between these prediction based energy estimates arises due to differences in their harmonic analyses. According to Byun [12], monthly harmonic analyses for tidal current velocities and 
heights observed in a narrow waterway exhibit a similar, 6-month-period, sine-curve form for the $\mathrm{S}_{2}$ harmonic constants (amplitudes and phase-lags).

When the available data spans less than a synodic month, neighboring tidal harmonic constituents (e.g., $\mathrm{S}_{2}$ and $\mathrm{K}_{2}$ ) can be forcibly separated out using an inference method [13]. Thus, the monthly variation in the $\mathrm{S}_{2}$ tidal current-velocity constants can be adjusted. Note that we conducted tidal current harmonic analyses using an inference method for the three one-year prediction-based energy estimations above. We explore change in the semi-major axes of the $\mathrm{M}_{2}$ and the $\mathrm{S}_{2}$ tidal constituents, which are the predominant harmonic constituents, for the three experiment cases: Exp-msn versus Exp-psn (Figure 5a,b); Exp-msn versus Exp-asn (Figure 5c,d); and Exp-asn versus Exp-psn (Figure 5e,f), for the $\mathrm{M}_{2}$ and the $\mathrm{S}_{2}$ semi-major axes, respectively. As shown in Figure 5a,c,e, the correlations of determination $\left(\mathrm{R}^{2}\right)$, slope values $\left(\beta_{1}\right)$ and regression-line intercepts $\left(\beta_{\mathrm{o}}\right)$ clearly show that values of the $\mathrm{M}_{2}$ semi-major axes are relatively stable across different time spans (15 versus 29 days) and tidal periods (apogee and perigee): 0.98 to 0.99 for $\mathrm{R}^{2}, 0.944$ to 1.100 for $\beta_{1}$ and 0.002 to 0.004 for $\beta_{0}$. The Root-Mean-Square Differences (RMSDs) were $0.04 \mathrm{~m} \mathrm{~s}^{-1}$ for each perigean (Exp-psn) and apogean (Exp-asn) dataset versus the one-month dataset (Exp-msn), whereas the RMSD between Exp-psn and Exp-asn was $0.07 \mathrm{~m} \cdot \mathrm{s}^{-1}$. In contrast to the $\mathrm{M}_{2}$, the $\mathrm{S}_{2}$ semi-major axes were less stable for the different time spans and tidal periods as shown in Figure 5 b,d,f: 0.80 to 0.94 for $\mathrm{R}^{2}$, 0.838 to 1.024 for $\beta_{1}$ and -0.001 to 0.026 for $\beta_{\mathrm{o}}$. The RMSDs for "Exp-msn versus Exp-psn" and “Exp-msn versus Exp-asn” were $0.03 \mathrm{~m} \cdot \mathrm{s}^{-1}$, while for the case of 'Exp-asn versus Exp-psn' the RMSD was $0.06 \mathrm{~m} \cdot \mathrm{s}^{-1}$. Similar to Byun's [12] findings, our experiments reveal that calculations involving the $\mathrm{S}_{2}$ semi-major axes (which are around three times smaller than those of the $\mathrm{M}_{2}$ ) are more strongly affected by the use of shorter, 15-day data sets (i.e., the apogee or perigee data alone) than those of the $\mathrm{M}_{2}$ semi-major axes. Further, the 29-day observation-derived annual energy density estimates ( $\overline{E_{A d_{-} M o b s}}$ ) for the three experiments were around $22 \%$ to $25 \%$ higher than the prediction-derived estimates $\left(\overline{E_{A d_{-} \text {Apre }}}\right)$ (Table 3$)$. The reason for this difference is that observed current records contain non-periodic currents induced by wind and hydrographic variations in addition to the periodic tidal-current components.

Two additional experiments were run to show the effects on 2011 annual energy density predictions of including (Case 1) versus excluding (Case 2) the effect of the $\mathrm{N}_{2}$ constituent. That is, Case 1 used 29-day harmonic-analysis based data including a perigean and apogean cycle, while Case 2 excluded this phenomenon. The year of 2011 was chosen for the prediction experiments because during this year the nodal factor value of the major tidal constituent, the $\mathrm{M}_{2}$, was close to 1 , which is the mean value of its whole 18.61 year cycle [14]. The mean annual energy density calculated including the $\mathrm{N}_{2}$ effect $\left(1.204 \mathrm{MWh} \cdot \mathrm{m}^{-2}\right)$ was found to exceed that calculated excluding $\mathrm{N}_{2}\left(1.142 \mathrm{MWh} \cdot \mathrm{m}^{-2}\right)$ by about $5.4 \%$.

These results reveal that at least a whole month of data is needed to accurately evaluate tidal current energy resources for environments with regimes dominated by perigean-apogean cycles. This is because current records of at least 27.55 days are required to harmonically separate out the $\mathrm{N}_{2}$ constituent from the $\mathrm{M}_{2}$ constituent, the former being responsible for generating the perigean and apogean components of the tidal current cycle and the semi-diurnal constituent with the $3^{\text {rd }}$ largest influence in such regimes, after the $\mathrm{M}_{2}$ and $\mathrm{S}_{2}$ constituents. 
Figure 5. Comparisons between (a,b) Exp-msn and Exp-psn, (c,d) Exp-msn and Exp-asn, $\left(\right.$ e,f) Exp-asn and Exp-psn for $\mathrm{M}_{2}$ and $\mathrm{S}_{2}$ semi-major axes $\left(\mathrm{a}_{\max }\right)$, respectively.
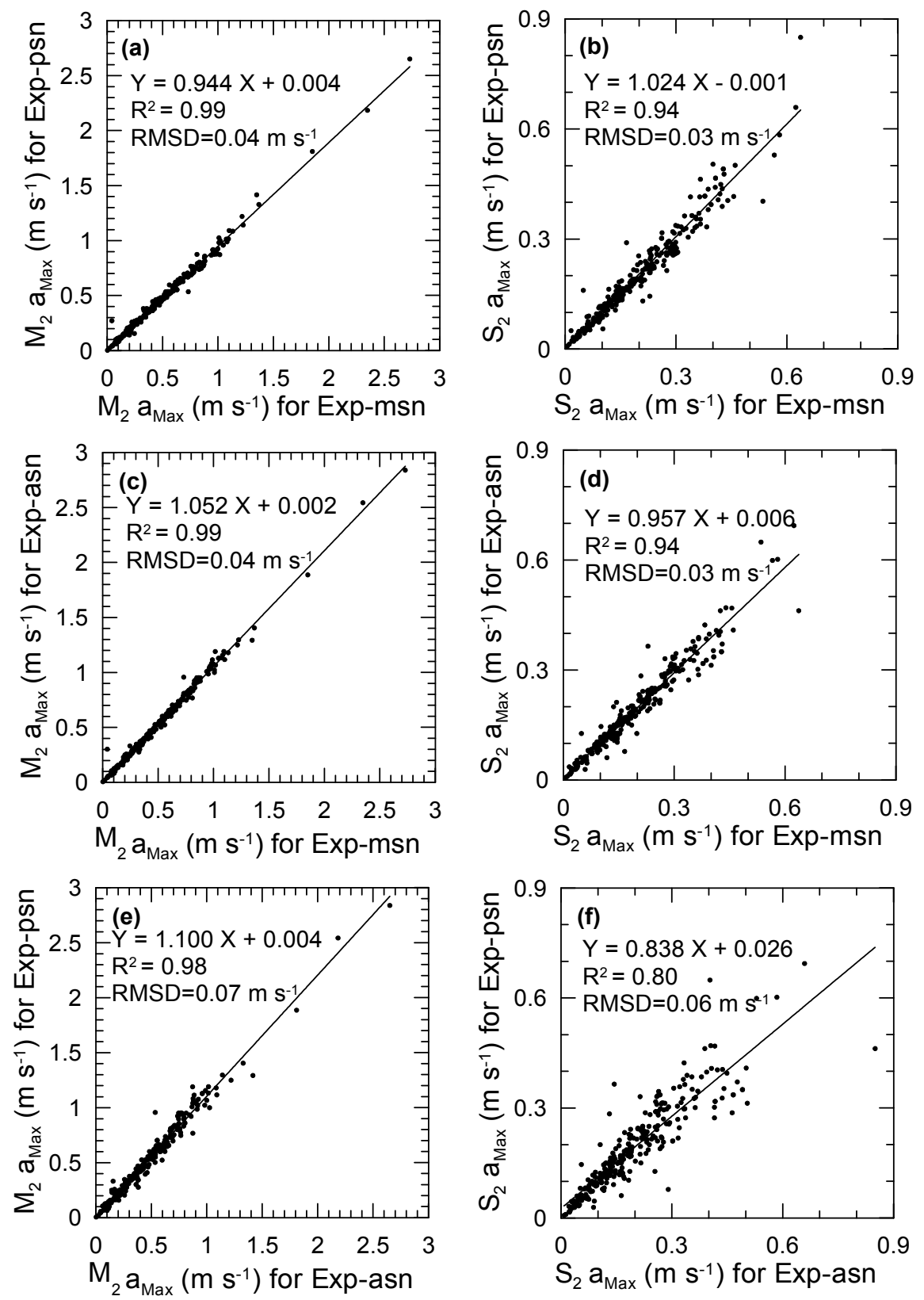

\section{Conclusions}

This preliminary study provides the initial assessment of the prospective tidal current resources of Korea's south and west coastal regimes needed to activate the country's green energy industry. Our information is based on in situ surface tidal current data observations from this renowned tidally-dominated environment. We show that high tidal current energy densities tend to occur in restricted waterways, since tidal current velocities are greatly affected by bathymetry. In addition, this study reveals that more than one month of observation data are required in order to accurately estimate the tidal current energy resources of a particular site due to the effect on these resources of the distinct perigean-apogean tidal current patterns, which can cause the resource to vary by $>5 \%$ over the course of a month. The methodology developed in this study can be applied to other tidally-dominated 
locations and results merged with other key criteria for tidal power developments, including water depth allowance, multiple sea space uses, and economic and environmental considerations, to facilitate the search for optimal sites.

Following on from this preliminary resource assessment, further detailed investigations need to be conducted for the higher energy sites into the horizontal and vertical patterns of tidal current velocity distributions in order to assess in situ tidal current energy resources with greater accuracy and to understand the characteristics of these environments with regard to optimal generator installation. The data we used comprised point-source observations recorded $\sim 5 \mathrm{~m}$ below the sea surface. However, in actuality, an array of energy generators would be installed to tap the currents across the entire usable width of any chosen waterway. As such and in addition to environmental impact assessments, detailed current profiles of the most energetic waterways identified in this study are needed for the next level of resource assessment, before individual installation sites can be chosen. Such detailed in situ tidal-current measurements could be obtained using trawler-resistant bottom-mounted Acoustic Doppler Current Profilers (ADCPs), Horizontal Acoustic Doppler Current Profilers (H-ADCPs) and ship-mounted ADCPs. In addition, a high resolution numerical modeling study, akin to that conducted for the Georgian Coast of the Unites States using the ROMS model by Defne et al. [10], could not only improve the estimation of prospective tidal current energy resources, but also narrow the search for optimal development sites.

\section{Acknowledgements}

The authors would like to gratefully acknowledge that both reviewers were helpful in improving the manuscript. This work was supported by the Ministry of Land, Transport and Maritime Affairs, Republic of Korea.

\section{References}

1. Esteban, M.; Leary, D. Current developments and future prospects of offshore wind and ocean energy. Appl. Energy 2012, 90, 128-136.

2. Triton Consultants Ltd. Green Energy Study for British Columbia Phase 2: Mainland Tidal Current Energy; Report prepared for BC Hydro, Vancouver, Canada, 2002.

3. Bahaj, A.S.; Myers, L. Analytical estimates of the energy yield potential from the Alderney Race (Channel Islands) using marine current energy converters. Renew. Energy 2004, 29, 1931-1945.

4. Carballo, R.; Iglesias, G.; Castro, A. Numerical model evaluation of tidal stream energy resources in the Ría de Muros (NW Spain). Renew. Energy 2009, 34, 1517-1524.

5. Bernitsas, M.M.; Raghavan, K.; Ben-Simon, Y.; Garcia, E.M.H. VIVACE (Vortex Induced Vibration Aquatic Clean Energy): A new concept in generation of clean and renewable energy from fluid flow. J. Offshore Mech. Arct. 2008, 130, 41101-41115.

6. Lunar Energy Harnessing Tidal Power Homepage. Available online: http://www.lunarenergy.co.uk/ (accessed on 8 March 2012).

7. Blunden, L.S.; Bahaj, A.S. Initial evaluation of tidal stream energy resources at Portland Bill, UK. Renew. Energy 2006, 31, 121-132. 
8. Goring, D.G.; Nikora, V.I. Despiking acoustic Doppler velocimeter data. J. Hydraul. Eng. 2002, 128, 117-126.

9. Pawlowicz, R.; Beardsley, B.; Lentz, S. Classical tidal harmonic analysis including error estimates in MATLAB using T_TIDE. Comput. Geosci. 2002, 28, 929-937.

10. Defne, Z.; Haas, K.A.; Fritz, H.M. Numerical modeling of tidal currents and the effects of power extraction on estuarine hydrodynamics along the Georgia coast, USA. Renew. Energy 2011, 36, 3461-3471.

11. Boon, J.D. Secrets of the Tide: Tide and Tidal Current Analysis and Applications, Storm Surges and Sea Level Trends; Horwood Publishing Limited: West Sussex, UK, 2004; pp. 17-19.

12. Byun, D.-S. Investigating the adjustment methods of monthly variability in tidal current harmonic constants. Ocean Polar Res. 2011, 33, 309-319.

13. Foreman, M.G.G. Manual for Tidal Currents Analysis and Prediction; Pacific Marine Science Report 78-6; Institute of Ocean Sciences: Patricia Bay, Sidney, BC, Canada, October 2004.

14. Byun, D.-S.; Cho, C.-W. Exploring conventional tidal prediction schemes for improved coastal numerical forecast modeling. Ocean Modell. 2009, 28, 193-202.

(C) 2013 by the authors; licensee MDPI, Basel, Switzerland. This article is an open access article distributed under the terms and conditions of the Creative Commons Attribution license (http://creativecommons.org/licenses/by/3.0/). 